\title{
Nutritional status of light-for-date infants at birth and its influence on early postnatal growth
}

\author{
D. P. DAVIES, P. PlATTS, J. M. PRITCHARD, AND P. W. WILKINSON \\ Department of Child Health, Leicester Royal Infirmary Maternity Hospital
}

SUMmaRY The ponderal index $(\mathrm{PI})\left(\mathrm{g} / \mathrm{cm}^{3} \times 100\right)$ was used to define the state of nutrition at birth of 47 light-for-date (LFD) term infants and to determine how intrauterine undernutrition influences growth during the first 6 months of postnatal life, at four age intervals: birth-4, 5-8, 9-12, 13-26 weeks. With the exception of one baby, each PI was $<50$ th centile on the Miller and Hassanein standards: in $24(51 \%)$ babies the PI was $<3$ rd centile. This suggests that, generally, LFD infants are underweight for length, and by inference, are likely to have experienced intrauterine undernutrition. In the first month the 24 'wasted' infants (PI $<3$ rd centile) gained more rapidly in weight, and grew more quickly in head circumference and length than the 16 'nonwasted' infants (PI $>10$ th centile). Thereafter growth rates were similar. With the exception of weight in the 'nonwasted' infants during the first month, rates of growth (weight, length, and head circumference) in both groups of babies in each of the 3 months after birth were greater than in normal infants. The first 3 months after birth can therefore be defined as the period of 'catch-up' growth in LFD term infants.

From their outward appearance light-for-date (LFD) infants who show no signs of congenital malformations or intrauterine infection can be differentiated according to the extent to which they show external signs of intrauterine undernutrition. Some show unmistakable features of wasting while others seem to show none, resembling instead 'perfect miniatures'. Little is known about postnatal growth after intrauterine undernutrition as no study of growth in LFD infants (for example Babson, 1970; Fitzhardinge and Steven, 1972; Brandt, 1976; Martell et al., 1978) has paid regard to the state of nutrition at birth. In the present study we used the ponderal index (PI) (Miller and Hassanein, 1971; Jarai et al., 1977) to investigate the nutritional status of LFD infants at birth, and to see how intrauterine undernutrition affects growth during the first 6 months of postnatal life.

\section{Materials and methods}

Study infants. 47 consecutively born term infants were studied: all were white and singletons. None had any

\footnotetext{
Department of Child Health, Leicester Royal Infirmary

D. P. DAVIES, senior lecturer

P. PLATTS, senior house officer

J. M. PRITCHARD, senior house officer

Department of Child Health, Clatterbridge Hospital, Wirral, Merseyside

P. W. WILKINSON, consultant paediatrician
}

congenital malformation or any external feature of intrauterine infection. The weight of each infant was $<5$ th centile for gestation, allowing for sex, mother's height, and birth order (Tanner and Thomson, 1970). Weight, length, and head circumference were measured (D.P.D.) between 24 and 48 hours of age, using methods previously described (Davies, 1976). For each infant the PI $\left(\mathrm{g} / \mathrm{cm}^{3} \times 100\right)$ was calculated and according to the distribution on the centile standards of Miller and Hassanein (1971) two groups of infants were defined:

\section{Group 1, 'wasted'}

24 infants whose PIs were $<3$ rd centile for gestation.

\section{Group 2, 'nonwasted'}

16 infants whose PIs were $>10$ th centile for gestation.

Seven infants in whom the PI was between the 3rd and 10th centiles were not included in the final analysis.

Evaluation of growth. Measurements of weight, length, and head circumference were made (D.P.D.) at $1,2,3$, and 6 months $( \pm 3$ days of the projected date). Individual growth velocities were calculated for 4 age intervals (birth-4, 5-8, 9-12, 13-26 weeks). Mean values were calculated and the statistical significance of any differences was tested by Student's $t$ test. 
As well as comparing growth rates between the two groups of LFD infants, comparisons were made with infants in whom the rate of intrauterine growth had been normal. For this purpose, velocity growth curves for weight, length, and head circumference were constructed from data on 50 term infants of appropriate weights for gestation, who had also been seen at birth, and at 1, 2, 3, and 6 months (P. W. Wilkinson, unpublished observations).

\section{Results}

Distribution of PI. Fig. 1 shows the distribution of each PI for the 47 babies according to the Miller and Hassanein standards. All, except one baby, were $<50$ th centile and $24(51 \%)$ were $<3$ rd centile.

Birth data. Mean values for gestational age, weight, length, head circumference, and PI at birth in both groups of infants are shown in Table 1. Group 1 infants were on average $83 \mathrm{~g}$ lighter and $1 \mathrm{~cm}$ longer than those in group 2, but the mean values for head circumference were the same.

Growth. Rates of weight gain, length, and head circumference are given in Table 2 . Weight, length, and head circumference growth rates were significantly higher $(\mathrm{P}<0.01)$ in group 1 infants during

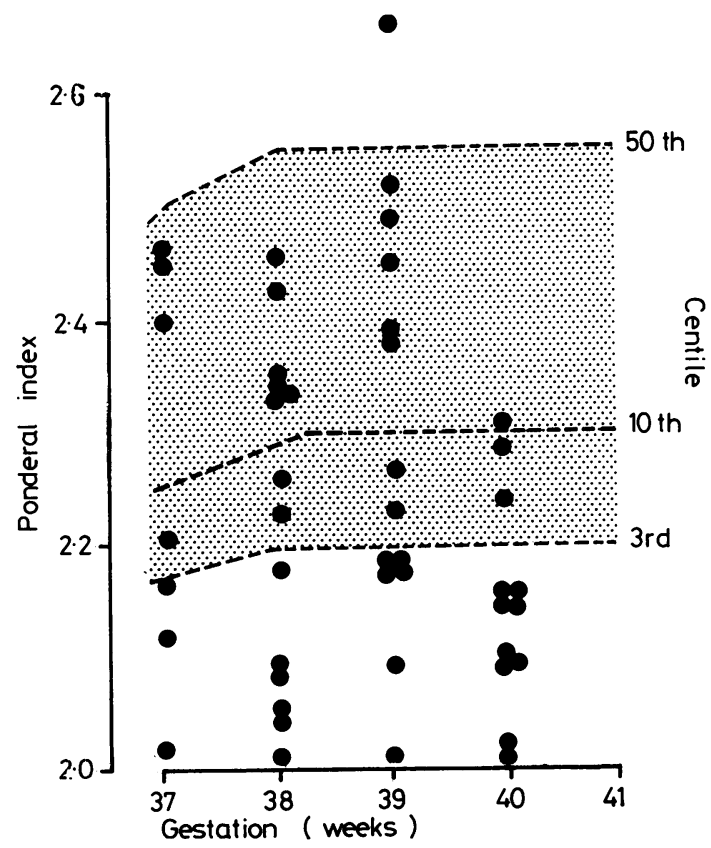

Fig. 1 Distribution of the 47 ponderal indices on the centile standards of Miller and Hassanein (1971). the first month. Thereafter the growth velocities showed no significant differences.

Figs 2-4 show the velocity growth curves for groups 1 and 2 compared with normal infants. Except for weight in the first month in infants in group 2, the mean curves of weight gain, length,

Table 1 Birth data in 'wasted' (group 1) and 'nonwasted' (group 2) LFD infants. Mean values (SE of mean)

\begin{tabular}{lcc}
\hline Birth data & $\begin{array}{l}\text { Group } 1 \\
(n=24)\end{array}$ & $\begin{array}{l}\text { Group } 2 \\
(n=16)\end{array}$ \\
\hline Gestational age (weeks) & $38 \cdot 3(0 \cdot 41)$ & $38 \cdot 7(0 \cdot 36)$ \\
Ponderal index: $\left(\mathrm{g} \times 100 / \mathrm{cm}^{3}\right)$ & $2 \cdot 19(0 \cdot 02)$ & $2 \cdot 43(0 \cdot 06)$ \\
Weight $(\mathrm{g})$ & $2097(54)$ & $2180(45)$ \\
Crown-heel length $(\mathrm{cm})$ & $45 \cdot 7(0 \cdot 79)$ & $44 \cdot 7(0 \cdot 28)$ \\
Head circumference $(\mathrm{cm})$ & $32 \cdot 1(0 \cdot 24)$ & $32 \cdot 1(0 \cdot 45)$ \\
\hline
\end{tabular}

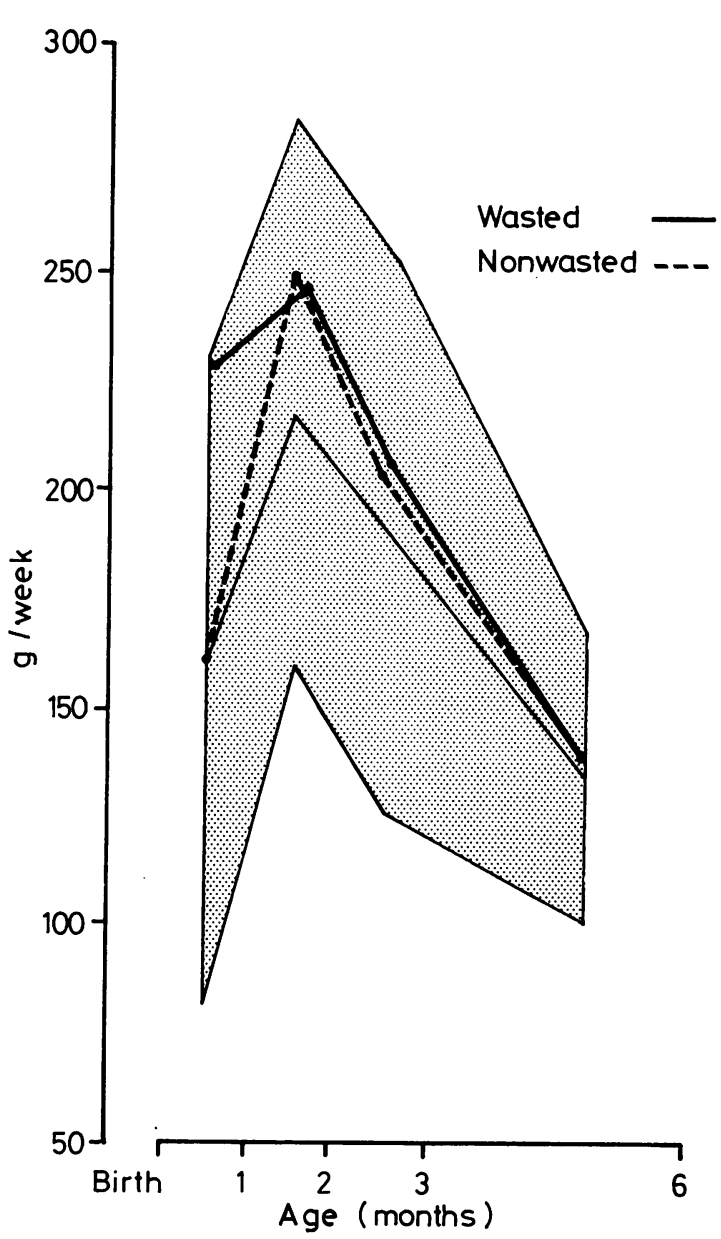

Fig. 2 Curves of mean weight gain velocities in LFD term infants. Shaded area represents the mean $\pm 1 S D$ weight gain velocity of 50 normal term infants. 
Table 2 Comparisons of weekly growth rates in 'wasted' (group 1) and 'nonwasted' (group 2) LFD infants. Mean values (SE of mean)

\begin{tabular}{|c|c|c|c|c|}
\hline $\begin{array}{l}\text { Age } \\
\text { (weeks) }\end{array}$ & Group & $\begin{array}{l}\text { Weight } \\
(g)\end{array}$ & $\begin{array}{l}\text { Length } \\
(\mathrm{mm})\end{array}$ & $\begin{array}{l}\text { Head } \\
\text { circumference } \\
(\mathrm{mm})\end{array}$ \\
\hline Birth-4 & $\begin{array}{c}1(n=24) \\
2(n=16) \\
P<0.01\end{array}$ & $\begin{array}{l}228(16) \\
160(12)\end{array}$ & $\begin{array}{r}10.5(0.63) \\
8.6(0.57)\end{array}$ & $\begin{array}{l}7 \cdot 1(0.34) \\
5 \cdot 7(0.56)\end{array}$ \\
\hline $5-8$ & $\begin{array}{l}1 \\
2\end{array}$ & $\begin{array}{l}246(19) \\
248(19)\end{array}$ & $\begin{array}{l}9.1(0.48) \\
9.8(0.62)\end{array}$ & $\begin{array}{l}5.7(0.43) \\
5.7(0.39)\end{array}$ \\
\hline $9-12$ & $\begin{array}{l}1 \\
2\end{array}$ & $\begin{array}{l}207(13) \\
204(12)\end{array}$ & $\begin{array}{l}7.9(0.53) \\
7.5(0.54)\end{array}$ & $\begin{array}{l}4 \cdot 1(0.28) \\
4.0(0.35)\end{array}$ \\
\hline $13-26$ & $\begin{array}{l}1 \\
2\end{array}$ & $\begin{array}{l}142(14) \\
143(14)\end{array}$ & $\begin{array}{l}5.1(0.51) \\
4.8(0.34)\end{array}$ & $\begin{array}{l}2.4(0.31) \\
2.7(0.29)\end{array}$ \\
\hline
\end{tabular}

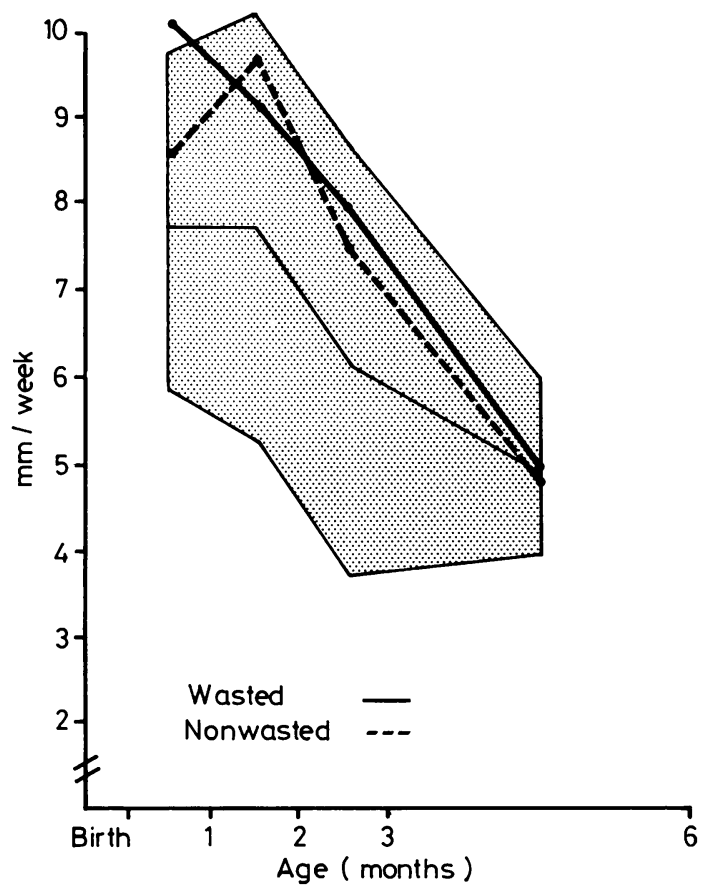

Fig. 3 Curves of mean length growth velocities in LFD term infants. Shaded area represents the mean $\pm 1 S D$ length growth velocity of 50 normal term infants.

and head circumference growth in infants in both groups were consistently higher than those for normal infants during the first 3 months. At between 3 and 6 months the growth rates in both LFD categories were close to normal.

\section{Discussion}

The fact that all but one infant had a PI $<50$ th centile at birth suggests that in general LFD infants are underweight for length and likely therefore to have experienced, to a variable extent, inadequate

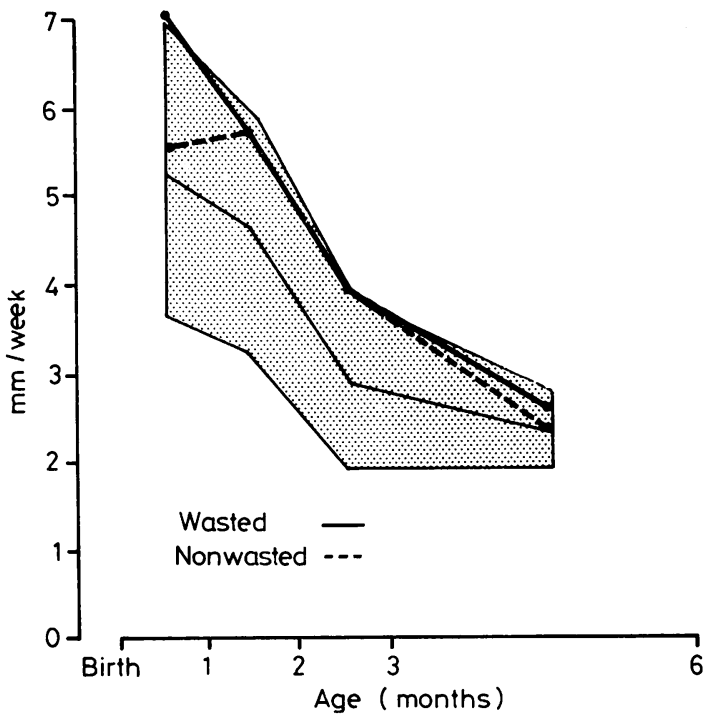

Fig. 4 Curves of mean head circumference growth velocities in LFD term infants. Shaded area represents the mean $\pm 1 S D$ head circumference growth velocity of 50 normal term infants.

intrauterine nutrition. This is further supported by the observation that 'nonwasted' as well as 'wasted' infants showed above average growth rates in the first 3 months after birth. Campbell showed by intrauterine biparietal cephalometry that as many as 20 to $30 \%$ of LFD infants at birth had symmetrical growth retardation due to reduced fetal growth potential (Campbell, 1974). Our data suggest that the proportion of LFD infants who show symmetrical growth retardation is smaller. Indeed our two groups might have been more appropriately termed 'wasted' and 'not-so-wasted' as there would appear to be a continuum of intrauterine undernutrition from those severely affected to those much less affected.

In view of the greater than normal growth rates in LFD infants in the first 3 months, this period can be defined as 'the catch-up period'. Furthermore, the fact that during the first month the infants in group 1 grew more rapidly than those in group 2 suggests that much of the intrauterine growth deficit is made up very early in postnatal life. These observations are at variance with Widdowson (1974) who, in a study of the effects of intrauterine undernutrition on postnatal growth in small animals wrote: 'In animals, the rate of growth after birth is related to the size at birth, and the same on the whole is true in man.' Our data show that this is clearly not the case for the newborn human infant who has been underfed in intrauterine life. 
We thank the mothers of all the babies who participated in this study, several of our colleagues for criticism, and Mrs F. Quinton and Miss S. Mangal for secretarial assistance.

\section{References}

Babson, S. G. (1970). Growth of low birthweight infants. Journal of Pediatrics, 77, 11-18.

Brandt, I. (1976). Dynamics of head circumference growth before and after term. In The Biology of Human Fetal Growth, pp. 109-136. Edited by D. F. Roberts and A. M. Thomson. Taylor and Francis: London.

Campbell, S. (1974). Physical methods of assessing size at birth. In Size at Birth. Ciba Foundation Symposium 27, pp. 275-293. Edited by K. M. Elliott and J. Knight. Elsevier: Amsterdam.

Davies, D. P. (1976). Adequacy of expressed breast milk for early growth of preterm infants. Archives of Disease in Childhood, 52, 296-301.

Fitzhardinge, P. M., and Steven, E. M. (1972). The small-fordate infant. I. Later growth patterns. Pediatrics, 49, 671681.

Jarai, I., Mestyan, J., Schultz, K., Lazar, A., Halasz, M., and Krassy, I. (1977). Body size and neonatal hypoglycemia in intra-uterine growth retardation. Early Human Development, 1, 25-38.

Martell, M., Falkner, F., Bertolini, L. B., Diaz, J. L., Nicto, F., Tenzer, S. M., and Belitzky, R. (1978). Early post-natal growth evaluation in full term, preterm, and small-for-dates infants. Early Human Development, 1, 313-322.

Miller, H. C., and Hassanein, K. (1971). Diagnosis of impaired fetal growth in newborn infants. Pediatrics, 48, 511-522.

Tanner, J. M., and Thomson, A. M. (1970). Standards for birthweight at gestation periods from 32 to 42 weeks, allowing for maternal height and weight. Archives of Disease in Childhood, 45, 566-569.

Widdowson, E. M. (1974). Immediate and long-term consequences of being large or small at birth: a comparative approach. In Size at Birth. Ciba Foundation Symposium 27, pp. 65-75. Edited by K. M. Elliott and J. Knight. Elsevier: Amsterdam.

Correspondence to Dr D. P. Davies, Department of Child Health, Leicester Royal Infirmary, Leicester LE1 5WW.

Received 12 December 1978 